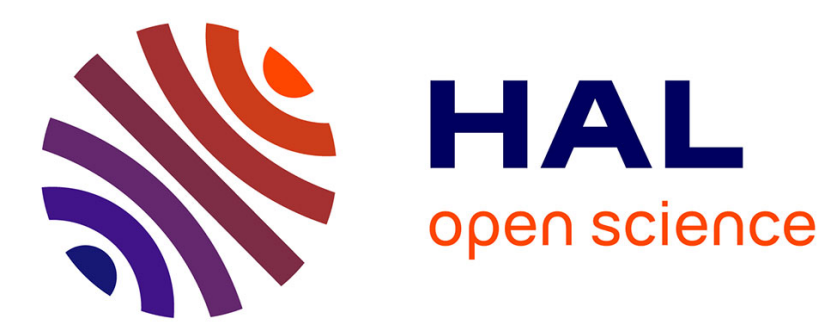

\title{
Providing choice and/or variety during a meal: Impact on vegetable liking and intake
}

Odile Parizel, Hélène Labouré, Agnès Marsset-Baglieri, Gilles Fromentin, Claire Sulmont-Rossé

\section{- To cite this version:}

Odile Parizel, Hélène Labouré, Agnès Marsset-Baglieri, Gilles Fromentin, Claire Sulmont-Rossé. Providing choice and/or variety during a meal: Impact on vegetable liking and intake. Appetite, 2017, 108, pp.391 - 398. 10.1016/j.appet.2016.10.027 . hal-01468522

\section{HAL Id: hal-01468522 \\ https://u-bourgogne.hal.science/hal-01468522}

Submitted on 18 Feb 2021

HAL is a multi-disciplinary open access archive for the deposit and dissemination of scientific research documents, whether they are published or not. The documents may come from teaching and research institutions in France or abroad, or from public or private research centers.
L'archive ouverte pluridisciplinaire HAL, est destinée au dépôt et à la diffusion de documents scientifiques de niveau recherche, publiés ou non, émanant des établissements d'enseignement et de recherche français ou étrangers, des laboratoires publics ou privés. 


\section{PROVIDING CHOICE AND/OR VARIETY DURING A MEAL: IMPACT ON VEGETABLE LIKING AND INTAKE}

Authors: Odile Parizel ${ }^{\mathrm{a}, \mathrm{b}}$, Hélène Labouré ${ }^{\mathrm{a}, \mathrm{c}}$, Agnès Marsset-Baglieri ${ }^{\mathrm{b}}$, Gilles Fromentin ${ }^{\mathrm{b}}$, Claire Sulmont-Rossé a

${ }^{a}$ Centre des Sciences du Goût et de l'Alimentation, CNRS, INRA, Univ. Bourgogne FrancheComté, F-21000 Dijon, France.

${ }^{\mathrm{b}}$ UMR Physiologie de la Nutrition et du Comportement Alimentaire, AgroParisTech, INRA, Université Paris-Saclay, F-75005 Paris, France

${ }^{c}$ AgroSup Dijon, F-21000 Dijon, France

Corresponding author: Claire Sulmont-Rossé, CSGA-INRA, 17 rue Sully, 21000 Dijon, France. E-mail: claire.sulmont@dijon.inra.fr, Phone number: (33)-380-69-32-71 


\section{ABSTRACT}

Out-of-home catering services frequently offer consumers the opportunity to choose their foods from among different proposals and/or provide consumers with a variety of food. The aim of the present study was to assess the impact of choice and/or variety on food liking and food intake. Fifty-nine normal-weight adults were recruited under the condition that they equally liked three vegetable recipes (green beans with butter, zucchinis with olive oil, spinach with cream). Volunteers participated in four sessions at lunch time. In the no-choice/no-variety condition, volunteers were served one dish randomly selected from among the three. In the nochoice/variety condition, volunteers were served all three dishes. In the choice/no-variety condition, participants chose one dish from among the three dishes. In the choice/variety condition, volunteers chose as many dishes as they desired from among the three dishes. Results showed that providing choice increased vegetable liking and vegetable intake, while offering a variety of vegetables only increased their liking. No synergy effect between choice and variety was observed on vegetable liking and vegetable intake (i.e. the effect in the choice/variety condition was not significantly higher than the effects in no-choice/variety and the choice/novariety conditions).

\section{KEYWORDS}

Food choice; food variety; food intake; food liking; plate clearers; eating behavior

\section{HIGHLIGHTS}

Providing choice increases vegetable liking.

Providing variety increases vegetable liking.

Providing choice increases vegetable intake. 


\section{INTRODUCTION}

Nowadays, out-of-home catering provides individuals some degree of freedom regarding food selection: it is common that people select their dishes from among several proposals (e.g. choice of one starter among several) and/or combine several alternatives for the same course (e.g. selecting two side dishes for the main course). Consequently, people often face a choice situation (e.g. making a decision about the food to be consumed) and/or a variety situation (e.g. being exposed to multiple foods). However, both choice and variety have been demonstrated to influence food liking and food intake.

Food choice is defined as providing the opportunity for an individual to select the food he or she wants to consume (Parizel et al., 2016). Several authors have observed a positive effect of providing food choice on food liking and/or food intake in adults (King, Meiselman, \& Henriques, 2008; King, Meiselman, Hottenstein, Work, \& Cronk, 2007; King, Weber, Meiselman, \& Lv, 2004), children (Altintzoglou et al., 2015; de Wild, de Graaf, Boshuizen, \& Jager, 2015; Rohlfs Domínguez et al., 2013; Zeinstra, Koelen, Kok, van der Laan, \& de Graaf, 2010) and elderly individuals (Kremer, Derks, Nijenhuis, Boer, \& Gorselink, 2012; Nijs, Graaf,

Kok, \& Staveren, 2006). For instance, Altintzoglou et al. (2015) observed a positive effect of choice on fish liking when children (11-12 years old) chose the fish they wanted to taste from among two alternatives, compared to a no-choice situation in which children were assigned one of the two fishes. Rohlfs Domínguez et al. (2013) observed a $120 \%$ increase in vegetable intake when children (Spanish, 4-6 years old) were allowed to choose the vegetable they wanted to consume for their school lunch from among two alternatives, compared to a no-choice situation. Recently, we observed that providing choice led to an increase in both food liking and food intake when French adults were allowed to choose the dessert they wanted to consume from 
among three alternatives, compared to a situation in which they were randomly assigned one of the three (Parizel et al., 2016). Several authors have demonstrated that choice has a powerful motivating effect: people are more likely to engage in an activity, and to succeed and enjoy it, if they had chosen it (Patall, Cooper, \& Robinson, 2008). According to the self-determination theory, people are naturally inclined to interact with the environment in a way that promotes three psychological needs: the need for competence (i.e. feeling effective), for autonomy (i.e. feeling of being the perceived origin of a behavior) and for relatedness (i.e. feeling connected to others) (Deci \& Ryan, 2002). Social contexts that fulfil these needs will thus enhance intrinsic motivation, namely the desire to carry out an activity for self-gratification (as opposed to extrinsic motivation, related to the desire to carry out an activity for external rewards). Providing choice is one way to enhance a person's experience of competence and autonomy (Langer, 1975; Ryan \& Deci, 2000). Consequently, the self-determination theory holds that choice should result in positive intrinsic motivation, which in turn leads to higher performance and satisfaction (Patall et al., 2008). When applied to the subject of food, one can expect that providing the opportunity for an individual to choose the food he or she wants to consume would elicit an increased motivation to eat, as well as greater food enjoyment.

Food variety is defined as providing an individual with foods that differ on at least one sensory characteristic (Raynor \& Epstein, 2001). Again, several authors have observed a positive effect of providing food variety on food intake within a meal (McCrory, Burke, \& Roberts, 2012; Meengs, Roe, \& Rolls, 2012; Pliner, Polivy, Herman, \& Zakalusny, 1980; Raynor \& Epstein, 2001; Rolls et al., 1981; Spiegel \& Stellar, 1990). For instance, Meengs et al. (2012) observed that participants ate more vegetables when served three types of vegetables side by side (simultaneous variety) than when served only one type. Barbara J. Rolls et al. (1981) showed that participants 
ate more when offered a variety of food in succession (sequential variety) (sandwiches with four different fillings; three different flavored-yoghurts) than when offered the same food throughout a meal. In their review of literature, McCrory et al. (2012) found an average increase of $22 \%$ in food intake (amount or energy) when providing food variety within a meal (the meta-analysis was based on 10 within-subject design studies assessing sequential and simultaneous variety). It has been argued that providing food variety may prevent the onset of specific-sensory satiation that refers to a drop in pleasantness of an eaten food aroused by its ingestion in contrast to other non-eaten foods. In fact, Rolls, Rolls, Rowe, \& Sweeney (1981) observed that liking decreased more for an eaten food than a non-eaten food and that these changes in liking were highly correlated with subsequent food intake: participants ate more when they were served a different food (the "non-eaten food") than when they were served the same food (the "eaten food"). However, in some studies, variety also increased food selection, even if participants did not consume the foods (Bucher, Siegrist, \& van der Horst, 2014; Keenan, Brunstrom, \& Ferriday, 2015; Wilkinson, Hinton, Fay, Rogers, \& Brunstrom, 2013). Bucher et al. (2014) observed that children served themselves significantly more vegetables when presented with two vegetables than only one. Wilkinson et al. (2013) argued that variety may affect the cognitive representation of food quantities, which in turn may increase served portions. In fact, these authors showed that participants increased their anticipated pleasantness and selected a larger portion to eat when provided with a sequential variety of foods compared to a no-variety condition.

Literature then shows that providing food choice or providing food variety may increase meal enjoyment and food intake. Until the present moment, these two factors have been mainly investigated separately, while they may actually co-occur in real-life settings. In fact, in many out-of-home catering situations, individuals have the possibility to choose as many dishes as they 
desire from among different proposals for their meal. Consequently, the aim of the present study was to assess the impact of choice and/or variety on food liking and food intake during a lunch. Specifically, four conditions that may occur in real life were compared: (i) participants were served with one dish randomly selected from among three alternatives (no-choice/no-variety condition); (ii) participants chose one dish from among three alternatives (choice/no-variety condition); (iii) participants were served with the three dishes (no-choice/variety condition); and (iv) participants chose as many dishes as they desired from among three alternatives (choice/variety condition).

\section{MATERIALS AND METHODS}

\section{The food products}

Three green vegetable recipes were selected from 27 recipes by an on-line questionnaire carried out by 205 French adults (a separate group from the participants in the present study). For each recipe, these adults were asked to indicate if they had already tasted it and then to rate their liking according to a 10-point hedonic scale ranging from "I do not like it at all" (0) to "I like it very much" (10). They were also asked to indicate their frequency of consumption ("more than 5 times per year"; "between 1 and 5 times per year"; "less than one time per year"). The results allowed us to select recipes that are commonly eaten and similarly liked by French adults. These recipes consisted in green beans with butter (mean liking: $\mathrm{M}=7.4, \mathrm{SEM}=0.1$ ), zucchinis with olive oil (mean liking: $\mathrm{M}=7.7, \mathrm{SEM}=0.2$ ) and spinach with cream (mean liking: $\mathrm{M}=7.4$, $\mathrm{SEM}=0.2)$.

The green beans (extra-fine frozen green beans, Thiriet ${ }^{\circledR}$ ), the zucchinis (frozen zucchinis, Thiriet $\left(\right.$ ) and the spinach (frozen spinach leaves, Thiriet ${ }^{\circledR}$ ) were cooked in a pressure cooker at 1 
bar for $90 \mathrm{sec}, 130 \mathrm{sec}$ and $85 \mathrm{sec}$, respectively. Then, they were seasoned with butter $(1.6 \mathrm{~g}$ per $100 \mathrm{~g}$ of cooked green beans), olive oil (3.4 g per $100 \mathrm{~g}$ of cooked zucchinis) or $30 \%$-fat cream (7.9 g per $100 \mathrm{~g}$ of cooked spinach), respectively. The amount of fatty ingredient added in each dish was adjusted so that the difference in energy content did not exceed 20 kcal while still fitting typical French culinary habits. Lastly, all the vegetables were seasoned with salt $(0.15 / 100 \mathrm{~g})$ and pepper $(0.035 / 100 \mathrm{~g})$. The nutritional content of each dish is displayed on Table 1 . The dishes were prepared 2 hours before each meal and reheated in a microwave just before being served, the serving temperature being between 50 and $60^{\circ} \mathrm{C}$.

\section{Table 1 about here}

\section{Participants}

Fifty-nine healthy and normal weight volunteers were recruited from Dijon (France) and its surroundings between January and April 2015. The recruitment criteria were as follows: aged between 18 and 40 years old; having a normal and stable weight (BMI between 18.5 and 26 $\mathrm{kg} / \mathrm{m}^{2}$ and no weight variation greater than $3 \mathrm{~kg}$ during the last three months); scoring lower than 14 on the restraint scale and lower than 12 on the disinhibition scale of the Three Factor Eating Questionnaire (Stunkard \& Messick, 1985) (Harden, Corfe, Richardson, Dettmar, \& Paxman, 2009); not taking any drugs liable to have an impact on appetite (e.g. corticoids, antidepressants); not on a diet; non-smoker; not abusing alcohol; neither pregnant nor breastfeeding; not allergic to any ingredients proposed during the study and having already eaten the vegetable dishes before. Furthermore, candidates were asked to rate their liking for the three selected recipes (green beans with butter, zucchinis with olive oil, spinach with cream) on a 10-point hedonic scale in an online questionnaire. To be recruited, a candidate had to have similar liking scores for the recipes 
(i.e. the liking scores of the three recipes differed by no more than 2 points on the hedonic scale) and could not have rejected any of the recipes (i.e. the liking scores should be higher than 2 points for the three recipes).

With the aim of preventing any biases due to change in their behavior, participants were unaware of the real purpose of the experiment (i.e. to study the impact of choice and/or variety on food liking and food intake) and were told that the experiment was designed to study the influence of tea on satiety. The experimental protocol was approved by the French Ethics Committee for Research CPP Est I (\#2014-A01709-38). The participants received financial compensation for their participation.

\section{Experimental design}

Participants took part in four sessions during lunch (the order of the sessions was balanced across participants according to a Williams Latin square):

- a no-choice/no-variety session (NC/NV): the participant was served one vegetable dish that was randomly selected from among the three vegetable dishes;

- a choice/no-variety session (C/NV): the participant was simultaneously presented the three vegetable dishes and asked to choose one of the three;

- a no-choice/variety session (NC/V): the participant was served the three vegetable dishes side by side;

- a choice/variety session $(\mathrm{C} / \mathrm{V})$ : the participant was simultaneously presented the three vegetable dishes and asked to choose as many dishes as he or she desired.

Sessions were separated by at least 4 days. 


\section{Procedure}

The participants were asked to have the same breakfast each test day at least three hours before the session and not to eat or drink (except water) until the session (sessions started at 12:00). For each session, the participants were served a main course of ham (Monique Ranouß), with vegetables as described in the following. For the choice condition $(\mathrm{C} / \mathrm{NV}$ and $\mathrm{C} / \mathrm{V})$, the three vegetable dishes were displayed in small portions in front of each participant in a random order. The participants were asked to choose one of the dishes $(\mathrm{C} / \mathrm{NV})$ or as many dishes as they desired $(\mathrm{C} / \mathrm{V})$ without tasting them first. They could not see one another's choices in order to rule out any social influence on choice. Whatever the condition, the participants received $400 \pm 2 \mathrm{~g}$ of vegetables: when they were served one vegetable dish $(\mathrm{NC} / \mathrm{NV}, \mathrm{C} / \mathrm{NV}$ and when a participant chose one dish in C/V), they were given $400 \pm 2 \mathrm{~g}$ of this dish (Fig. 1); when they were served two vegetable dishes (when a participant chose two dishes in C/V), they were given $200 \pm 2 \mathrm{~g}$ of each dish; when they were served three vegetable dishes $(\mathrm{NC} / \mathrm{V}$ and when a participant chose three dishes in $\mathrm{C} / \mathrm{V}$ ), they were given $133 \pm 2 \mathrm{~g}$ of each dish. The participants were allowed to eat as much vegetables as they desired. A second helping was systematically proposed to participants who finished their plate.

During the first session, the participants were instructed to eat as many slices of ham as they desired, and the amount that each participant consumed was recorded. During the following sessions, the participants were served the amount of ham that they had consumed during session 1 and were asked to eat the full portion. Each participant then consumed the same amount of ham with vegetables throughout all the sessions. After the main course, the participants were served a 350 g portion of apple puree (Compote de Pommes Morceaux Andros ${ }^{\circledR}$ ) and were allowed to consume the quantity they desired. At the end of each session, they were offered a cup of tea that 
varied in flavor throughout the four sessions. At each session, participants were offered mineral water (Evian). The sessions were carried out in a room deprived of food references and the participants sat in individual booths.

Figure 1 about here

\section{Measurements}

The participants' food and water intake was measured by weighing the plates before and after consumption (accuracy: $\pm 1 \mathrm{~g}$ ). The participants rated their feeling of hunger on a $100 \mathrm{~mm}$ visual analog scale ranging from "I am not at all hungry" to "I am extremely hungry" before eating, after the main course and after the meal. They rated their liking for the vegetable course, the ham and the apple puree after the meal according to a 10-point hedonic scale ranging from "I do not like it at all" (0) to "I like it very much" (10). The participants also rated their feeling of hunger one hour after the meal to credit the false pretense of the study (i.e. study the influence of tea on satiety), but these data were not analyzed.

At the end of the last session, the participants rated their liking for each vegetable dish on a 10point hedonic scale. Finally, each participant was weighed and there height was measured.

\section{Data analysis}

Main outcomes. Liking scores collected at the end of the meal for the vegetable course (vegetable liking) and the quantities of vegetables consumed (vegetable intake) were submitted to two different linear mixed models:

- A two-factor linear mixed model with condition (NC/NV; NC/V; C/NV; C/V) and session position as fixed factors and participant as random factor. This model enabled the comparison of the four conditions of vegetable presentations. 
- A three-factor linear mixed model with choice (choice; no-choice), variety (variety; novariety), their interaction and session position as fixed factors, and participant as random factor. This model would emphasize the occurrence of a choice effect and/or a variety effect by comparing the choice sessions $(\mathrm{C} / \mathrm{NV}$ and $\mathrm{C} / \mathrm{V})$ with the no-choice sessions $(\mathrm{NC} / \mathrm{NV}$ and $\mathrm{NC} / \mathrm{V})$ and the variety sessions $(\mathrm{C} / \mathrm{V}$ and $\mathrm{NC} / \mathrm{V})$ with the no-variety sessions $(\mathrm{C} / \mathrm{NV}$ and $\mathrm{NC} / \mathrm{NV})$, respectively.

Session position corresponds to the order of the sessions and was taken into account to investigate a possible effect of tiredness throughout the four sessions.

Secondary outcomes. Liking scores collected at the end of the last session for each vegetable dish were submitted to a one-factor linear mixed model with dish as fixed factor and participant as random factor. Hunger scores collected during the four sessions were submitted to a two-factor linear mixed model with condition $(\mathrm{NC} / \mathrm{NV} ; \mathrm{NC} / \mathrm{V} ; \mathrm{C} / \mathrm{NV} ; \mathrm{C} / \mathrm{V})$ and session position as fixed factors and participant as random factor.

Statistical analyses were conducted using R with the "nlme" package for linear mixed models and the "lsmeans" package for post-hoc analyses (without adjustment)(R Development Core Team, 2006). Means (M) were associated with their standard errors (SEM). The threshold for significance was set at $5 \%$.

\section{RESULTS}

Fifty-nine volunteers were initially recruited in this study but two volunteers did not attend all sessions and three volunteers under-estimated their weight (over $26 \mathrm{~kg} / \mathrm{m}^{2}$ ) in the on-line recruitment questionnaire. Their data were removed from the final dataset. The final dataset included 54 participants ( 47 women and 7 men) with an average age of 27.4 years $(\mathrm{SD}=6.8)$, an 
average BMI of $21.7 \mathrm{~kg} / \mathrm{m}^{2}(\mathrm{SD}=2.1)$ and average scores of TFEQ-D and TFEQ-R of 6.1 $(\mathrm{SD}=2.5)$ and $6.7(\mathrm{SD}=3.4)$, respectively.

Among these 54 volunteers, ten participants ate the whole portion(s) of vegetable(s) that was (were) served on their plate throughout the four conditions: 8 participants systematically cleared their vegetable plate for the first helping and did not ask for a second helping; 2 participants systematically cleared the first helping, asked at some sessions for a second helping and likewise cleared it. On average, these participants ate $409 \mathrm{~g}(\mathrm{SEM}=7)$ of vegetables throughout the four sessions. The tendency to eat the whole portion on one's plate refers to a so-called "plate clearing” behavior (Robinson, Aveyard, \& Jebb, 2015). As it may be hypothesized that for plate clearers, food intake mainly depends on the quantity of food served on their plate rather than on external signals such as contextual factors, the statistical analyses were conducted for the whole population $(n=54)$ and for the population without the plate clearers $(n=44)$.

\section{Main outcomes}

The mean consumption of vegetable, ham, apple puree and water in the 4 conditions are presented in Table 2.

\section{Table 2 about here}

Table 3 presents the results of the two-factor and three-factor linear mixed models on vegetable liking and vegetable intake for the population with and without plate clearers. We did not observe any session position effect on vegetable liking or vegetable intake.

Table 3 about here 
Whole population $(n=54)$. The two-factor model revealed a significant condition effect on vegetable liking $(\mathrm{F}(3,154)=12.28, \mathrm{p}<0.001)$ but not on vegetable intake. According to post-hoc analyses, participants gave higher liking scores to the vegetable course in the choice/variety than in the no-choice/variety condition, which is associated with higher liking score than the nochoice/no-variety condition. The choice/no-variety condition is intermediate between the choice/variety and no-choice/variety conditions (Fig. 2). The three-factor model revealed significant choice and variety effects on vegetable liking (choice: $F(1,154)=22.15, p<0.001$; variety: $\mathrm{F}(1,154)=11.54, \mathrm{p}<0.001)$ and an almost significant effect of choice on vegetable intake $(\mathrm{F}(1,154)=2.89, \mathrm{p}=0.09)$. Participants gave higher liking scores to the vegetable course and tended to eat more vegetables when provided choice (liking: $\mathrm{M}=7.7, \mathrm{SEM}=0.1$; intake: $\mathrm{M}=340 \mathrm{~g}$, $\mathrm{SEM}=8$ ) compared to the no-choice conditions (liking: $\mathrm{M}=7.0, \mathrm{SEM}=0.2$; intake: $\mathrm{M}=326 \mathrm{~g}$, $\mathrm{SEM}=10$ ). They also gave higher liking scores to the vegetable course in variety conditions $(\mathrm{M}=7.6, \mathrm{SEM}=0.1)$ compared to the no-variety conditions $(\mathrm{M}=7.1, \mathrm{SEM}=0.2)$. Providing choice led to a $10 \%$ increase in liking compared to not having choice while providing variety led to a $7 \%$ increase in liking compared to offering only one vegetable dish.

\section{Figure 2 about here}

Without plate clearers $(n=44)$. The two-factor model also revealed a significant condition effect on vegetable liking $(F(3,154)=10.59, \mathrm{p}<0.001)$ and on vegetable intake $(\mathrm{F}(3,154)=2.86, \mathrm{p}<0.05)$. According to post-hoc analyses, participants gave higher liking scores in no-choice/variety, choice/no-variety and choice/variety conditions than in the no-choice/no-variety condition, and ate more in choice/no-variety and choice/variety conditions than in the no-choice/no-variety condition (Fig. 3). The three-factor model revealed significant choice and variety effects on vegetable liking (choice: $F(1,124)=18.91, p<0.001$; variety: $F(1,124)=9.68, p<0.01$ ) and a 
significant choice effect on vegetable intake $(\mathrm{F}(1,124)=5.51, \mathrm{p}<0.05)$. Participants gave higher liking scores in choice situations $(\mathrm{M}=7.6, \mathrm{SEM}=0.2)$ than in no-choice situations $(\mathrm{M}=6.8$, SEM=0.2). They also gave higher liking scores to the vegetable course in variety conditions $(\mathrm{M}=7.5, \mathrm{SEM}=0.2)$ compared to the no-variety conditions $(\mathrm{M}=6.9, \mathrm{SEM}=0.2)$. Participants ate more vegetables in choice conditions $(\mathrm{M}=326 \mathrm{~g}, \mathrm{SEM}=9)$ than in no-choice conditions $(\mathrm{M}=305$ $\mathrm{g}, \mathrm{SEM}=11$ ). Providing choice led to a $12 \%$ increase in liking and a $7 \%$ increase in intake compared to not having choice. Providing variety led to a $9 \%$ increase in liking compared to offering only one vegetable dish.

\section{Figure 3 about here}

In the choice/variety condition, participants were asked to choose as many dishes as they desired from among three proposals. In this condition, 32 and 12 participants chose two and three vegetable dishes, respectively, while 10 participants chose only one vegetable dish. Senso strictu,

the latter were not in a variety condition when eating the main course (they only had one vegetable dish served on their plate). However, when these participants were removed for data analysis, we observed the same pattern of results, namely a choice effect $(F(1,97)=6.47 ; p<0.05)$ but no significant variety effect $(\mathrm{F}(1,97)=0.81 ; \mathrm{p}=0.37)$ on vegetable intake.

\section{Secondary outcomes}

Vegetable dish pleasantness. No significant dish effect was observed on the liking scores collected at the end of the last session for each vegetable dish, either for the whole population (green beans: $\mathrm{M}=6.8, \mathrm{SEM}=0.3$; zucchinis: $\mathrm{M}=7.4$; $\mathrm{SEM}=0.3$; spinach: $\mathrm{M}=7.0$; $\mathrm{SEM}=0.3$ ) or for participants without plate clearers (green beans: $\mathrm{M}=6.6, \mathrm{SEM}=0.3$; zucchinis: $\mathrm{M}=7.2$; $\mathrm{SEM}=0.3$; spinach: $\mathrm{M}=7.0 ; \mathrm{SEM}=0.3$ ). There was an average difference of $\mathrm{M}=2.6$ ( $\mathrm{SEM}=0.3$ ) points 
between the liking scores of the three vegetable recipes for the whole population, and $\mathrm{M}=2.8$ $(\mathrm{SEM}=0.3)$ points for the participants without plate clearers.

Hunger sensation. For the whole population, the two-factor model did not reveal any significant condition effects on hunger scores collected before eating, after the main course or after the meal. Results revealed a significant session position effect after the main course $(F(3,153)=3.39$, $\mathrm{p}<0.05$ ), but no effect before eating and after the meal. Hunger scores after the main course at the session $1(\mathrm{M}=5.2, \mathrm{SEM}=1.1)$ were lesser than scores at sessions $3(\mathrm{M}=8.2, \mathrm{SEM}=1.4)$ and 4 $(\mathrm{M}=9.9, \mathrm{SEM}=1.9)$.

For the population without plate clearers, the two-factor model did not reveal any significant condition effect on hunger scores collected before eating, after the main course or after the meal. Results revealed a significant session position effect after the main course $(F(3,124)=3.51$, $\mathrm{p}<0.05)$ but no effect before eating and after the meal. After the main course, hunger scores at the session $1(M=5.2, S E M=1.3)$ were lesser than scores at sessions $3(M=8.9, S E M=1.6)$ and 4 $(\mathrm{M}=8.6, \mathrm{SEM}=1.5)$.

As we hypothesized that for plate clearers, food intake mainly depends on the quantity of food served on their plate rather than on external signals such as contextual factors, we calculated the correlation between hunger scores collected before the meal and food intake for non-clearers and plate-clearers. A significant correlation was observed for the non-clearers (Pearson coefficient: $R=0.17 ; p<0.05$ for vegetable intake; $R=0.22 ; p<0.01$ for meal intake) but not for the plateclearers (Pearson coefficient: $R=0.08 ; p=0.63$ for vegetable intake; $R=0.11 ; p=0.48$ for meal intake). 


\section{DISCUSSION}

This study aimed at comparing the effects of providing choice and/or variety on food intake and food liking. Results showed that both choice and variety increase food liking for the population with and without plate clearers. Nevertheless, we only observed a significant increasing effect of choice on the quantities of vegetables consumed for participants that were not plate clearers (participants who did not clear their plate at each session). We did not find any variety effect on vegetable intake. We observed no synergy effect between choice and variety on vegetable liking and vegetable intake (i.e. the effect in the choice/variety condition was not significantly higher than the effects in the no-choice/variety and choice/no-variety conditions). However, food liking and food intake in the no-choice \& no-variety condition tended to be smaller than the other conditions, and we can note rule out that a large sample size might have revealed significant interactions.

The impact of choice on food liking and food intake corroborates previous results obtained in similar experimental conditions (Altintzoglou et al., 2015; Parizel et al., 2016; Rohlfs Domínguez et al., 2013). According to the self-determination theory, providing choice fulfills the consumer's needs for competence and autonomy and thus promotes higher intrinsic motivation, which in turn leads to higher satisfaction and engagement (Patall et al., 2008; Ryan \& Deci, 2000). However, it has also been argued that the impact of choice on food behavior may result from the fact that offering choice gives consumers the opportunity to choose their favorite food among proposals with might lead to higher consumption (Yeomans, 1996; De Graaf et al., 1999; Bolhuis et al., 2012). In the present experiment, this "preference" effect was minimized by recruiting participants who gave similar liking scores to the three vegetables, in order to study the impact of choice per se. Accordingly, liking ratings performed at the end of the study did not reveal 
significant differences between the three vegetable dishes. However, it cannot be ruled out that some participants ate more in the choice and variety conditions because they were given the opportunity to eat the vegetable dish(es) they individually preferred in these conditions compared to the no-choice/no-variety condition. Furthermore, to make the variety condition as close as possible to a natural setting, participants were not explicitly asked to consume each of the vegetable dishes served on their plate. Rather, they were free to consume the vegetable dishes they desired. Actually, one consumer ate two vegetable dishes while the 53 others ate three vegetable dishes in the no-choice/variety condition, but the presence of choice in this condition cannot be ruled out: participants were free to choose the dishes they wanted to consume from among the dishes that were served on the plate. Accordingly, Zeinstra, Renes, Koelen, Kok, \& Graaf (2010) and Rohlfs Domínguez et al. (2013) compared a situation in which children were asked to choose one vegetable dish from among two proposals with a situation in which children were served a plate containing both vegetable dishes. The authors likewise acknowledged that the latter situation involved choice in addition to variety. This may account for the fact that in the present experiment, the difference between the no-choice and choice conditions tended to be higher in the no-variety condition than in the variety condition (Figure 2).

Results of the present experiment did not show a significant effect of simultaneous variety on vegetable intake, contrary to what was expected from the literature (Meengs et al., 2012; Bucher et al., 2014; Spiegel \& Stellar, 1990; Pliner et al., 1980). For instance, Meengs et al. (2012) observed an increase in vegetable intake when consumers were served three vegetables on their plate compared to situations where consumers received a single vegetable. Bucher et al. (2014) showed that children served themselves higher amount of vegetable in a variety condition (carrot and peas) compared to a no-variety condition (carrot or peas). The discrepancy between the 
results from this study and those in the literature may result from a difference in perceived variety of the assortment. In the present experiment, participants were served three vegetable dishes that varied in shape, taste and texture but not in color (green vegetables), while in the study by Meengs et al. (2012) participants were served three vegetables dishes that also varied in color (carrot, broccoli and peas). In fact, Rolls et al. (1981) observed that variety had a greater effect on food intake when participants were served yogurts that varied in taste, appearance and texture, than when participants were served yogurts that varied in flavor only. In a series of studies, Kahn \& Wansink (2004) demonstrated that the structure of an assortment moderates the effect of variety on food intake. For instance, they observed an increase of consumption when the number of colors increased in an assortment of M\&M's (10 colors versus 7 colors) providing that the distribution of the colors is asymmetric (i.e., colors are not presented at the same frequency). Furthermore, Redden (2006) showed that the enjoyment of eating jelly beans decreased faster when participants considered the candies as being part of a single general category ("jelly bean") than when participants considered the candies as belonging to different flavor-based subcategories (e.g. "cherry jelly bean", “orange jelly bean"). The author suggested that individuals paid more attention to the differences between the alternatives when achieving subcategorization, and thus perceived the successive eating episodes to be less repetitive. Consequently, consumers who consider their foods as belonging to different subcategories were less satiated. In the present experiment it may be hypothesized that participants considered the three vegetable dishes as belonging to the general category "green vegetables" instead of three different subcategories (i.e. "green beans", "zucchinis", “spinach"). Another possible limitation of the present study that may explain the lack of a variety effect on intake is the fact in the choice/variety condition, participants were asked to choose as many dishes as they desired from among three proposals. This was done to make the choice condition as close as possible to a real- 
life situation. In this condition, 10 participants chose only one vegetable dish and were not senso strictu in a variety condition when eating the main course (they only had one vegetable dish served on their plate). However, when these participants were removed for data analysis, we observed the same pattern of results on food intake (i.e. a choice effect but no significant variety effect).

Finally, we observed that 10 participants cleared their plate at each of the four sessions. The tendency to eat the whole portion on one's plate refers to a so-called "plate clearing" behavior (Robinson et al., 2015) and it has been observed that "plate clearers" finish their plate whether they choose the portion or were served the portion - as in the present experiment (Fay et al., 2011; Hinton et al., 2013; Robinson et al., 2015; Wansink \& Johnson, 2015). This behavior is purported to result either from early parental practices (Birch, McPheee, Shoba, Steinberg, \& Krehbiel, 1987) or from ethical concerns such as avoiding food wastage (Robinson et al., 2015). Consequently, it may be hypothesized that plate clearers show little sensitivity to internal signals such as hunger or external signals such as contextual factors: their food intake mainly depends on the quantity of food served on their plate. The analysis of results from individuals displaying no tendency of plate clearing showed an increasing effect of choice on their intake. These results emphasized that people are differently sensitive to signals of meal termination: when in the same state of hunger, some individuals mainly rely on the portion served on their plate while others are more sensitive to contextual factors, such as having choice. Interestingly, a significant correlation between hunger score collected before the meal and food intake (vegetable intake and meal intake) was observed for the non-clearers but not for the plate-clearers.

\section{CONCLUSION}


In conclusion, our results showed that providing choice and variety increased food liking, but only choice increased food intake. Contrary to our expectations, we did not observe any variety effect on food intake and therefore assumed that green vegetables did not arouse enough sensory dissimilarity. The present study did not reveal any synergy effect of providing choice and variety that might be related to the absence of variety effect. Further experiments using more dissimilar vegetables (varying in texture, taste and also color) would be needed before concluding that choice and variety do not interact.

\section{ACKNOWLEDGMENTS}

This work has been supported by a grant from the Institut National de la Recherche Agronomique (INRA, France) (métaprogramme DID’IT, PLEASIN project). This work was also supported by grants from the Regional Council of Burgundy France (PARI Agral 1) and the European Funding for Regional Economical Development (FEDER). We thank A. Bourgeois, F. Durey, V. Feyen, and E. Szleper for their participation in the collection of the data and C. Chabanet for her advice on statistical analysis.

\section{REFERENCES}

Altintzoglou, T., Skuland, A. V., Carlehög, M., Sone, I., Heide, M., \& Honkanen, P. (2015). Providing a food choice option increases children's liking of fish as part of a meal. Food Quality and Preference, 39, 117-123. http://doi.org/10.1016/j.foodqual.2014.06.013

Birch, L. L., McPheee, L., Shoba, B. ., Steinberg, L., \& Krehbiel, R. (1987). "Clean up your plate": Effects of child feeding practices on the conditioning of meal size. Learning and Motivation, 18(3), 301-317. http://doi.org/10.1016/0023-9690(87)90017-8 
Bucher, T., Siegrist, M., \& van der Horst, K. (2014). Vegetable variety: an effective strategy to increase vegetable choice in children. Public Health Nutrition, 17(6), 1232-1236. http://doi.org/10.1017/S1368980013002632

de Wild, V. W. T., de Graaf, C., Boshuizen, H. C., \& Jager, G. (2015). Influence of choice on vegetable intake in children: an in-home study. Appetite, 91, 1-6. http://doi.org/10.1016/j.appet.2015.03.025

Deci, E. L., \& Ryan, R. M. (2002). Overview of Self-Determination Theory: An Organismic Dialectical Perspective. In Handbook of Self-determination Research (University Rochester Press, pp. 3-33). R.M. Ryan \& E.L. Deci.

Fay, S. H., Ferriday, D., Hinton, E. C., Shakeshaft, N. G., Rogers, P. J., \& Brunstrom, J. M. (2011). What determines real-world meal size? Evidence for pre-meal planning. Appetite, 56(2), 284-289. http://doi.org/10.1016/j.appet.2011.01.006

Harden, C. J., Corfe, B. M., Richardson, J. C., Dettmar, P. W., \& Paxman, J. R. (2009). Body mass index and age affect Three-Factor Eating Questionnaire scores in male subjects. Nutrition Research, 29(6), 379-382. http://doi.org/10.1016/j.nutres.2009.04.001

Hinton, E. C., Brunstrom, J. M., Fay, S. H., Wilkinson, L. L., Ferriday, D., Rogers, P. J., \& de Wijk, R. (2013). Using photography in "The Restaurant of the Future". A useful way to assess portion selection and plate cleaning? Appetite, 63, 31-35. http://doi.org/10.1016/j.appet.2012.12.008

Kahn, B. E., \& Wansink, B. (2004). The Influence of Assortment Structure on Perceived Variety and Consumption Quantities. Journal of Consumer Research, 30(4), 519-533. http://doi.org/10.1086/jcr.2004.30.issue-4 
Keenan, G. S., Brunstrom, J. M., \& Ferriday, D. (2015a). Effects of meal variety on expected satiation: evidence for a "perceived volume" heuristic. Appetite, 89, 10-15. http://doi.org/10.1016/j.appet.2015.01.010

King, S. C., Meiselman, H. L., \& Henriques, A. (2008). The effect of choice and psychographics on the acceptability of novel flavors. Food Quality and Preference, 19(8), 692-696. http://doi.org/10.1016/j.foodqual.2008.05.003

King, S. C., Meiselman, H. L., Hottenstein, A. W., Work, T. M., \& Cronk, V. (2007). The effects of contextual variables on food acceptability: A confirmatory study. Food Quality and Preference, 18(1), 58-65. http://doi.org/10.1016/j.foodqual.2005.07.014

King, S. C., Weber, A. J., Meiselman, H. L., \& Lv, N. (2004). The effect of meal situation, social interaction, physical environment and choice on food acceptability. Food Quality and Preference, 15(7-8), 645-653. http://doi.org/10.1016/j.foodqual.2004.04.010

Kremer, S., Derks, J., Nijenhuis, M. A., Boer, E., \& Gorselink, M. (2012). Effect of a holistic meal and ambiance concept on main meal enjoyment and food intake of Dutch nursing home residents: A pilot study. Journal of Aging Research \& Clinical Practice, 1, 237244.

Langer, E. J. (1975). The illusion of control. Journal of Personality and Social Psychology, 32(2), 311-328. http://doi.org/10.1037/0022-3514.32.2.311

McCrory, M. A., Burke, A., \& Roberts, S. B. (2012). Dietary (sensory) variety and energy balance. Physiology \& Behavior, 107(4), 576-583. http://doi.org/10.1016/j.physbeh.2012.06.012

Meengs, J. S., Roe, L. S., \& Rolls, B. J. (2012). Vegetable variety: an effective strategy to increase vegetable intake in adults. Journal of the Academy of Nutrition and Dietetics, 112(8), 1211-1215. http://doi.org/10.1016/j.jand.2012.05.013 
Nijs, K. A. N. D., Graaf, C. de, Kok, F. J., \& Staveren, W. A. van. (2006). Effect of family style mealtimes on quality of life, physical performance, and body weight of nursing home residents: cluster randomised controlled trial. BMJ, 332(7551), 1180-1184. http://doi.org/10.1136/bmj.38825.401181.7C

Parizel, O., Sulmont-Rossé, C., Fromentin, G., Delarue, J., Labouré, H., Benamouzig, R., \& Marsset-Baglieri, A. (2016). The structure of a food product assortment modulates the effect of providing choice on food intake. Appetite, 104, 44-51. http://doi.org/10.1016/j.appet.2015.11.018

Patall, E. A., Cooper, H., \& Robinson, J. C. (2008). The effects of choice on intrinsic motivation and related outcomes: a meta-analysis of research findings. Psychological Bulletin, 134(2), 270-300. http://doi.org/10.1037/0033-2909.134.2.270

Pliner, P., Polivy, J., Herman, C. P., \& Zakalusny, I. (1980). Short-term intake of overweight individuals and normal weight dieters and non-dieters with and without choice among a variety of foods. Appetite, 1(3), 203-213. http://doi.org/10.1016/S0195-6663(80)80029-8

Raynor, H. A., \& Epstein, L. H. (2001). Dietary variety, energy regulation, and obesity. Psychological Bulletin, 127(3), 325-341.

Redden, J. P. (2006). Reducing satiation: The role of categorization level. Dissertations Available from ProQuest, 1-85.

Robinson, E., Aveyard, P., \& Jebb, S. A. (2015). Is plate clearing a risk factor for obesity? A cross-sectional study of self-reported data in US adults. Obesity (Silver Spring, Md.), 23(2), 301-304. http://doi.org/10.1002/oby.20976

Rohlfs Domínguez, P., Gámiz, F., Gil, M., Moreno, H., Márquez Zamora, R., Gallo, M., \& de Brugada, I. (2013). Providing choice increases children's vegetable intake. Food Quality and Preference, 30(2), 108-113. http://doi.org/10.1016/j.foodqual.2013.05.006 
Rolls, B. J., Rolls, E. T., Rowe, E. A., \& Sweeney, K. (1981). Sensory specific satiety in man. Physiology \& Behavior, 27(1), 137-142.

Rolls, B. J., Rowe, E. A., Rolls, E. T., Kingston, B., Megson, A., \& Gunary, R. (1981). Variety in a meal enhances food intake in man. Physiology \& Behavior, 26(2), 215-221. http://doi.org/10.1016/0031-9384(81)90014-7

Ryan, R. M., \& Deci, E. L. (2000). Self-determination theory and the facilitation of intrinsic motivation, social development, and well-being. American Psychologist, 55(1), 68-78. http://doi.org/10.1037/0003-066X.55.1.68

Spiegel, T. A., \& Stellar, E. (1990). Effects of variety on food intake of underweight, normalweight and overweight women. Appetite, 15(1), 47-61. http://doi.org/10.1016/01956663(90)90099-T

Stunkard, A. J., \& Messick, S. (1985). The three-factor eating questionnaire to measure dietary restraint, disinhibition and hunger. Journal of Psychosomatic Research, 29(1), 71-83.

Wansink, B., \& Johnson, K. A. (2015). The clean plate club: about 92\% of self-served food is eaten. International Journal of Obesity, 39(2), 371-374. http://doi.org/10.1038/ijo.2014.104

Wilkinson, L. L., Hinton, E. C., Fay, S. H., Rogers, P. J., \& Brunstrom, J. M. (2013a). The "variety effect" is anticipated in meal planning. Appetite, 60(1), 175-179. http://doi.org/10.1016/j.appet.2012.10.001

Zeinstra, G. G., Koelen, M. A., Kok, F. J., van der Laan, N., \& de Graaf, C. (2010). Parental child-feeding strategies in relation to Dutch children's fruit and vegetable intake. Public Health Nutrition, 13(6), 787-796. http://doi.org/10.1017/S1368980009991534

Zeinstra, G. G., Renes, R. J., Koelen, M. A., Kok, F. J., \& Graaf, C. de. (2010). Offering choice and its effect on Dutch children's liking and consumption of vegetables: a randomized 
controlled trial. The American Journal of Clinical Nutrition, 91(2), 349-356. http://doi.org/10.3945/ajcn.2009.28529 


\section{TABLE 1}

Nutritional composition of vegetable recipes

\begin{tabular}{lcccc}
\hline & $\begin{array}{c}\text { Energy } \\
(\mathbf{k c a l} / \mathbf{1 0 0 g})\end{array}$ & $\begin{array}{c}\text { Protein } \\
(\mathbf{g} / \mathbf{1 0 0 g})\end{array}$ & $\begin{array}{c}\text { Carbohydrates } \\
(\mathbf{g} / \mathbf{1 0 0 g})\end{array}$ & $\begin{array}{c}\text { Fat } \\
(\mathbf{g} / \mathbf{1 0 0 g})\end{array}$ \\
\hline Green beans with butter & 56 & 2.2 & 9.1 & 1.2 \\
Zucchinis with olive oil & 42.5 & 1.5 & 3.5 & 2.5 \\
Spinach with cream & 62.8 & 3.6 & 2.9 & 4.1 \\
\hline
\end{tabular}




\section{TABLE 2}

Mean quantities consumed of vegetable dishes, ham, apple puree and water for the whole population and the population without plate clearers in the no-choice/no-variety (NC/NV), nochoice/variety $(\mathrm{NC} / \mathrm{V})$, choice/no-variety $(\mathrm{C} / \mathrm{NV})$ and choice/variety $(\mathrm{C} / \mathrm{V})$ conditions. Results are expressed in mean $\pm \mathrm{SD}$.

\begin{tabular}{|c|c|c|c|c|c|}
\hline & & $\mathrm{NC} / \mathrm{NV}$ & $\mathrm{NC} / \mathrm{V}$ & $\mathbf{C} / \mathbf{N V}$ & $\mathbf{C} / \mathbf{V}$ \\
\hline \multirow[t]{5}{*}{$\begin{array}{l}\text { Whole population } \\
(\mathrm{n}=54)\end{array}$} & Vegetable $(g)^{a}$ & $318 \pm 98$ & $335 \pm 108$ & $340 \pm 91$ & $340 \pm 75$ \\
\hline & $\operatorname{Ham}(g)^{b}$ & $54 \pm 19$ & $54 \pm 19$ & $54 \pm 19$ & $54 \pm 19$ \\
\hline & Apple puree (g) ${ }^{c}$ & $266 \pm 101$ & $264 \pm 100$ & $263 \pm 100$ & $256 \pm 83$ \\
\hline & Water (ml) & $291 \pm 151$ & $319 \pm 162$ & $318 \pm 141$ & $300 \pm 156$ \\
\hline & Total energy intake (kcal) & $469 \pm 130$ & $478 \pm 136$ & $463 \pm 126$ & $468 \pm 104$ \\
\hline \multirow{5}{*}{$\begin{array}{l}\text { Without plate- } \\
\text { clearers }(n=44)\end{array}$} & Vegetable $(g)^{a}$ & $294 \pm 90$ & $316 \pm 108$ & $327 \pm 96$ & $326 \pm 77$ \\
\hline & $\operatorname{Ham}(g)^{b}$ & $51 \pm 18$ & $51 \pm 18$ & $51 \pm 18$ & $51 \pm 18$ \\
\hline & Apple puree (g) ${ }^{c}$ & $254 \pm 106$ & $257 \pm 105$ & $255 \pm 105$ & $247 \pm 85$ \\
\hline & Water (ml) & $300 \pm 157$ & $328 \pm 173$ & $325 \pm 146$ & $306 \pm 162$ \\
\hline & Total energy intake (kcal) & $441 \pm 128$ & $459 \pm 142$ & $451 \pm 134$ & $451 \pm 105$ \\
\hline
\end{tabular}

${ }^{a}$ Participants were served a $400 \pm 2$ g portion of vegetables, were allowed to eat as much vegetables as they desired and a second helping was systematically proposed to participants who finished their plate. ${ }^{\mathrm{b}}$ Participants were served the amount of ham that they had consumed during session 1 and were asked to eat the full portion in the subsequent 3 sessions. ${ }^{\mathrm{c}}$ Participants were served a 350 g portion of apple puree and were allowed to eat as much apple puree as they desired and a second helping was systematically proposed to participants who finished their plate. 


\section{TABLE 3}

Results of the two-factor and three-factor linear mixed model on vegetable liking and vegetable intake for the whole population and for the population without the plate clearers.

\begin{tabular}{|c|c|c|c|c|c|c|}
\hline Sample & Variable & Model & Factor & $\mathrm{n}$ & $\mathrm{F}$ & $\mathrm{p}$-value \\
\hline \multirow[t]{12}{*}{ Whole population } & \multirow[t]{6}{*}{ Vegetable liking } & \multirow[t]{2}{*}{ Two-factor } & condition & 154 & 12.28 & $<0.001$ \\
\hline & & & session position & 154 & 0.40 & 0.75 \\
\hline & & \multirow[t]{4}{*}{ Three-factor } & choice & 154 & 22.15 & $<0.001$ \\
\hline & & & variety & 154 & 11.54 & $<0.001$ \\
\hline & & & choice:variety & 154 & 3.39 & 0.07 \\
\hline & & & session position & 154 & 0.32 & 0.81 \\
\hline & \multirow[t]{6}{*}{ Vegetable intake } & \multirow[t]{2}{*}{ Two-factor } & condition & 154 & 1.85 & 0.14 \\
\hline & & & session position & 154 & 2.11 & 0.10 \\
\hline & & \multirow[t]{4}{*}{ Three-factor } & choice & 154 & 2.89 & 0.09 \\
\hline & & & variety & 154 & 0.99 & 0.32 \\
\hline & & & choice:variety & 154 & 1.25 & 0.27 \\
\hline & & & session position & 154 & 2.25 & 0.09 \\
\hline \multirow{12}{*}{$\begin{array}{l}\text { Without the } \\
\text { plate clearers }\end{array}$} & \multirow[t]{6}{*}{ Vegetable liking } & \multirow[t]{2}{*}{ Two-factor } & condition & 124 & 10.59 & $<0.001$ \\
\hline & & & session position & 124 & 0.14 & 0.93 \\
\hline & & \multirow[t]{4}{*}{ Three-factor } & choice & 124 & 18.91 & $<0.001$ \\
\hline & & & variety & 124 & 9.68 & $<0.01$ \\
\hline & & & choice:variety & 124 & 3.43 & 0.07 \\
\hline & & & session position & 124 & 0.06 & 0.98 \\
\hline & \multirow[t]{6}{*}{ Vegetable intake } & \multirow[t]{2}{*}{ Two-factor } & condition & 124 & 2.86 & $<0.05$ \\
\hline & & & session position & 124 & 1.18 & 0.32 \\
\hline & & \multirow[t]{4}{*}{ Three-factor } & choice & 124 & 5.51 & $<0.05$ \\
\hline & & & variety & 124 & 1.19 & 0.28 \\
\hline & & & choice:variety & 124 & 1.31 & 0.25 \\
\hline & & & session position & 124 & 1.37 & 0.26 \\
\hline
\end{tabular}




\section{FIGURE LEGENDS}

\section{FIGURE 1}

Pictures representing the $400 \mathrm{~g}$-portions of vegetables served to the participants (a: spinach with cream; b: green beans with butter; c: zucchinis with olive oil).

\section{FIGURE 2}

Mean liking scores of the consumed vegetable $( \pm \mathrm{SEM})(\mathrm{A})$, mean quantities of consumed vegetable $( \pm$ SEM) (B) for each condition for the whole population. Means with different letters $(a, b$ and $c)$ stand for significant differences $(p<0.05)$ (the $p$-values were obtained from post-hoc analyses (lsmeans package) following the 2-factor linear mixed model that revealed a condition effect)

\section{FIGURE 3}

Mean liking scores of the consumed vegetable $( \pm \mathrm{SEM})(\mathrm{A})$, mean quantities of consumed vegetable $( \pm$ SEM) (B) for each condition for the population without the plate clearers. Means with different letters $(a, b$ and $c)$ stand for significant differences $(p<0.05)$ (the $p$-values were obtained from post-hoc analyses (lsmeans package) following the 2-factor linear mixed model that revealed a condition effect) 


\section{FIGURE 1}
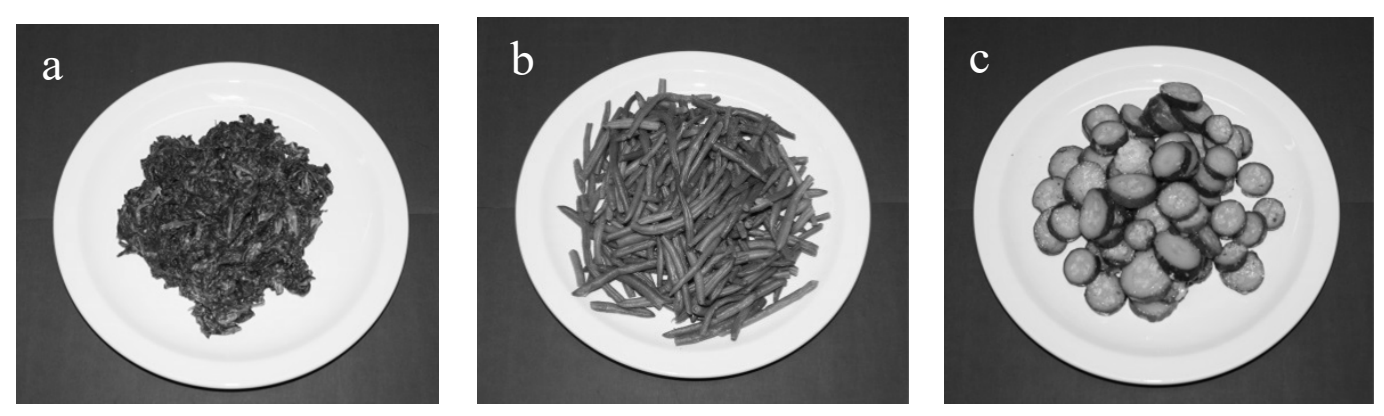

\section{FIGURE 2}
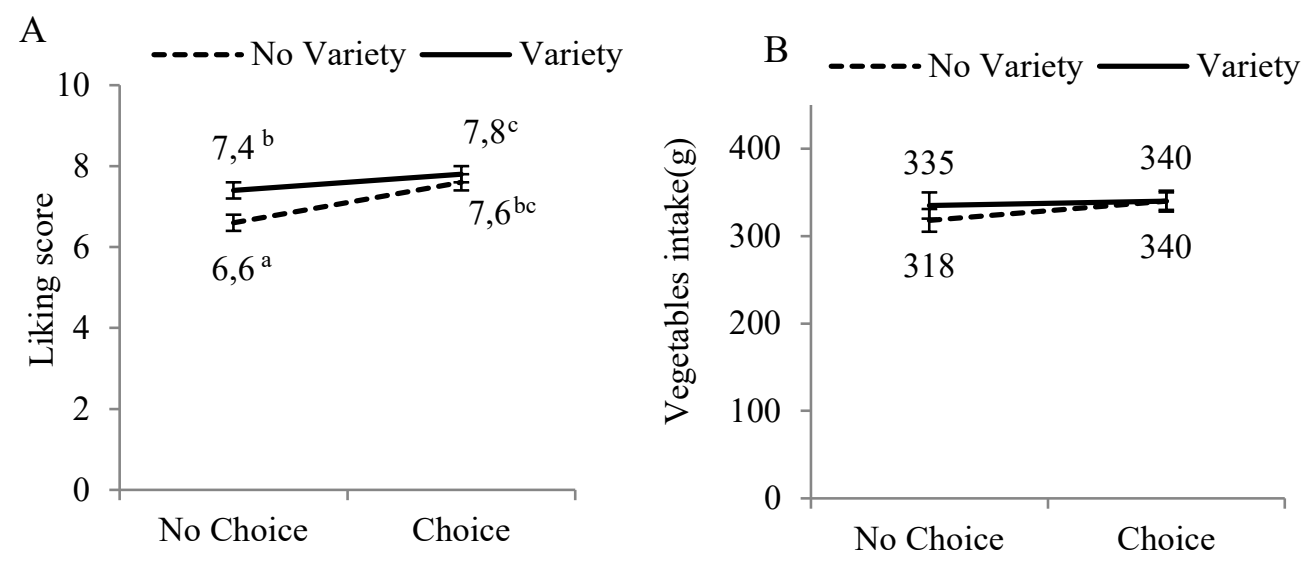

FIGURE 3
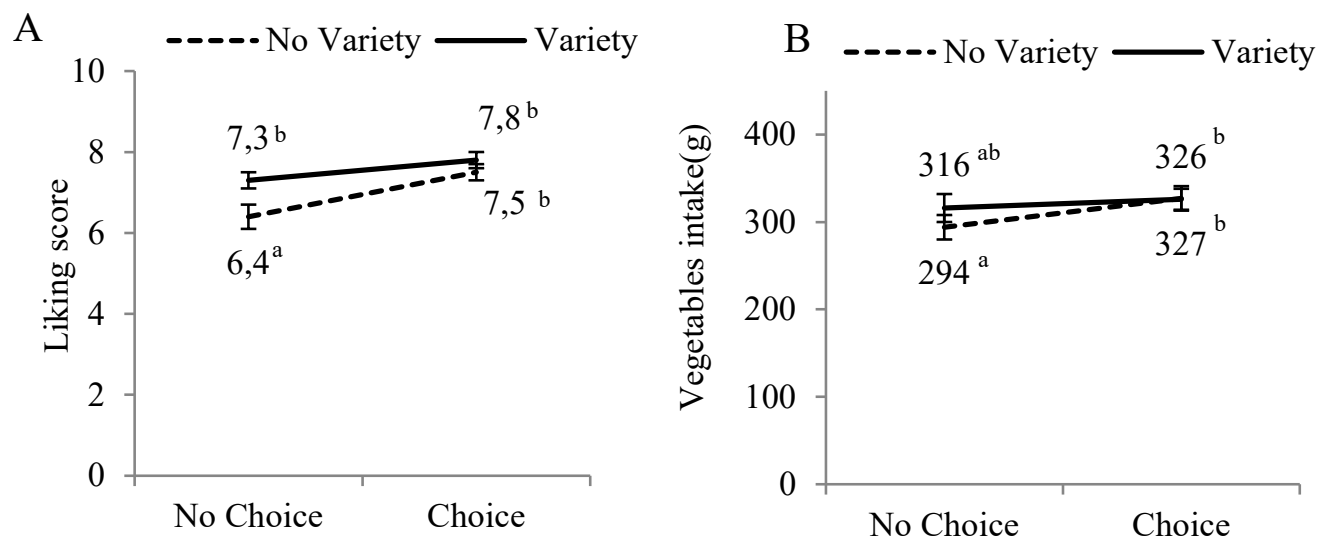